\title{
Increasing hematocrit above $28 \%$ during early resuscitative phase is not associated with decreased mortality following severe traumatic brain injury
}

\author{
Carole Flückiger • Markus Béchir • Mirko Brenni • \\ Silke Ludwig • Jutta Sommerfeld • Silvia R. Cottini • \\ Marius Keel • Reto Stocker • John F. Stover
}

Received: 20 July 2009 /Accepted: 4 December 2009 /Published online: 24 December 2009

(C) Springer-Verlag 2009

\begin{abstract}
Background To prevent iatrogenic damage, transfusions of red blood cells should be avoided. For this, specific and reliable transfusion triggers must be defined. To date, the optimal hematocrit during the initial operating room (OR) phase is still unclear in patients with severe traumatic brain injury (TBI). We hypothesized that hematocrit values exceeding $28 \%$, the local hematocrit target reached by the end of the initial OR phase, resulted in more complications, increased mortality, and impaired recovery compared to patients in whom hematocrit levels did not exceed $28 \%$.

Methods Impact of hematocrit (independent variable) reached by the end of the OR phase on mortality and morbidity determined by the extended Glasgow outcome scale (eGOS; dependent variables) was investigated retrospectively in 139 TBI patients. In addition, multiple logistic regression analysis was performed to identify additional important variables.

Findings Following severe TBI, mortality and morbidity were neither aggravated by hematocrit above $28 \%$ reached by the end of the OR phase nor worsened by the required
\end{abstract}

C. Flückiger $\cdot$ M. Béchir $\cdot$ S. Ludwig $\cdot$ J. Sommerfeld $\cdot$

S. R. Cottini $\cdot$ R. Stocker $\cdot$ J. F. Stover $(\bowtie)$

Surgical Intensive Care Medicine, University Hospital Zürich,

Raemistrasse 100,

8091 Zürich, Switzerland

e-mail: john.stover@access.unizh.ch

M. Brenni

Institute of Anesthesiology, University Hospital Zürich,

Zürich, Switzerland

M. Keel

Division of Trauma Surgery, University Hospital Zürich,

Zürich, Switzerland transfusions. Upon multiple logistic regression analysis, eGOS was significantly influenced by the highest intracranial pressure and the lowest cerebral perfusion pressure values during the initial OR phase.

Conclusions Based on this retrospective observational analysis, increasing hematocrit above $28 \%$ during the initial OR phase following severe TBI was not associated with improved or worsened outcome. This questions the need for aggressive transfusion management. Prospective analysis is required to determine the lowest acceptable hematocrit value during the OR phase which neither increases mortality nor impairs recovery. For this, a larger caseload and early monitoring of cerebral metabolism and oxygenation are indispensable.

Keywords Critical care · Emergency room · Intracranial pressure $\cdot$ Transfusion $\cdot$ Secondary brain injury

$\begin{array}{ll}\text { Abbreviations } \\ \text { CPP } & \text { Cerebral perfusion pressure } \\ \text { FFP } & \text { Fresh frozen plasma } \\ \text { ICP } & \text { Intracranial pressure } \\ \text { ICU } & \text { Intensive care unit } \\ \text { RBC } & \text { Red blood cells } \\ \text { TBI } & \text { Traumatic brain injury }\end{array}$

\section{Introduction}

Following severe traumatic brain injury (TBI), the injured brain is highly vulnerable to additional insults. The most deleterious secondary insults, which significantly increase mortality following TBI, are hypotension and hypoxia [21]. Tissue hypoxia associated with signs of disturbed cerebral 
metabolism [29], excitotoxicity [29], and long-term psychological impairment $[26,27]$ can be counteracted and prevented by maintaining adequate cerebral perfusion and improving tissue oxygen by additionally increasing $\mathrm{paO}_{2}$ [28] and transfusing red blood cells (RBCs) [18, 30].

To date, however, the optimal hemoglobin count remains poorly defined $[10,19,20]$. In brain-injured patients, hemoglobin of $10 \mathrm{~g} / \mathrm{dl}$ (hematocrit $30 \%$ ) is generally regarded adequate [17], which can only be reached by transfusing RBCs in patients with lower hematocrit levels. Transfusions, in turn, are associated with complications ranging from rare cases of transfusion-related viral and bacterial infections to the more common problems due to activated inflammatory, immunologic, and coagulation pathways $[2,14,23]$. Liberal transfusions with hemoglobin count $>10-12 \mathrm{~g} / \mathrm{dl}$ compared to $7-9 \mathrm{~g} / \mathrm{dl}$ have been repeatedly associated with increased mortality and morbidity reflected by infections, acute respiratory distress syndrome (ARDS), multiorgan failure, congestive heart failure, myocardial infarctions, and deep venous thrombosis in various patient groups [2, 33]. Several large multi-center prospective randomized and observational clinical trials performed in heterogeneous patient groups, i.e., Transfusion Requirements in Critical Care (TRICC) study, Anemia and Blood Transfusion in Critical Care study, and Anemia and Blood Transfusion in the Critically Ill study [3, 13, 41], showed that increasing hemoglobin above $10 \mathrm{~g} / \mathrm{dl}$ by transfusing RBCs was associated with the worse outcome. This, in turn, promoted the contemporary global restrictive transfusion practice. Post hoc analysis [22] and retrospective studies $[8,24]$ in TBI patients showed that the more restrictive transfusion strategy (7-9 g/dl) was comparable to the liberal strategy $(10-12 \mathrm{~g} / \mathrm{dl})$ in terms of similar mortality or morbidity during the intensive care unit (ICU) phase, thus justifying lower hematocrit levels in these patients. In their retrospective study, Carlson et al. could even show that prolonged duration of hematocrit $<30 \%$ during the ICU phase was associated with improved outcome following TBI [1].

The optimal hemoglobin content, however, remains to be defined especially during the acute phase in patients at risk of insufficient oxygen supply as, e.g., patients with severe TBI. To date, data investigating the impact of a specific hemoglobin/hematocrit transfusion threshold following severe TBI is limited to the ICU phase which is much more stable compared to the highly unstable and unpredictable emergency room (ER) and initial operating room (OR) phase. This early phase is characterized by various potentially deleterious influences, which can occur simultaneously as, e.g., anemia-inducing hemorrhages with consecutive hypotension, hypovolemia, coagulopathy, acidosis, as well as disturbed oxygenation with ensuing hypoxemia and hypoxia. Thus, it remains unclear whether a lower hematocrit is acceptable during the early phase and which is the lowest but still tolerable and safe hematocrit level.

Based on the general recommendations taken from the TRICC study and the findings by Carlson et al. [1], we hypothesized that patients with a hematocrit exceeding $28 \%$ reached by the end of the OR phase fare worse than patients with a hematocrit below $28 \%$, in terms of increased complications during the ICU, elevated overall in-hospital mortality, and worse outcome determined by extended Glasgow outcome scale (eGOS) after 6 months. For this, we investigated 139 patients suffering from severe TBI who were treated at the University Hospital from January 2004 to December 2006 who required intracranial pressure (ICP) monitoring and who were transferred to the trauma surgical ICU for further treatment.

\section{Materials and methods}

Inclusion criteria

The aims of the present retrospective study were to evaluate the influence of different hematocrit levels reached by the end of the initial OR phase on overall in-hospital mortality and morbidity. Inclusion criteria for the present study were patients suffering from severe TBI with and without additional injuries requiring continuous ICP monitoring. Patients succumbing within the first $24 \mathrm{~h}$ following TBI as well as those patients on oral anticoagulants or platelet inhibitors were excluded. Those patients who died within the first $24 \mathrm{~h}$ were too severely injured, and their treatment was already terminated in the OR before transferral to the ICU.

Following approval by the local ethics committee, which waived the need for written informed consent for this retrospective analysis, relevant information was transferred from patient records to an anonymized data bank using Microsoft Excel ${ }^{\circledR}$ and Microsoft Access ${ }^{\circledR}$. Only patients with a complete data set of the OR phase were considered for subsequent analysis. Patients treated at the University Hospital from January 1, 2004 to December 31, 2006 were considered in the present analysis.

Standardized management in the emergency room (ER) and operating room $(\mathrm{OR})$

Following initial hemodynamic and cardiopulmonary stabilization, radiologic/ultrasonographic diagnostic measures as well as surgical interventions according to the ATLS ${ }^{\circledR}$ guidelines were performed. An ICP probe (Neurovent ${ }^{\circledR}$, Raumedic, www.raumedic.de) was inserted in the OR adjacent to the ER during the ER/OR phase. Whenever the ORs were occupied, surgical procedures were performed in the equally equipped ER. Standard indications 
for ICP probe placement were typical trauma history including secondary neurologic worsening, pathologic neurological findings (Glasgow coma scale (GCS), $\leq 9$ ), and pathologic computed tomography (CT) findings. All patients were intubated and subjected to continuous analgesia and sedation using fentanyl (Sintenyl ${ }^{\circledR}$ ) and midazolam (Dormicum ${ }^{\circledR}$ ) with intermittent muscle relaxation (pancuronium, Pavulon ${ }^{\circledR}$ ). In addition to basic monitoring $\left(\mathrm{ECG}, \mathrm{SpO}_{2}\right.$, and etCO$\left.{ }_{2}\right)$, all patients received an arterial and central venous line and a urinary catheter. Hemodynamic stability was achieved by infusing crystalloids and colloids in addition to administration of norepinephrine and dobutamine, whenever required. These measures were guided by changes in lactate, urinary production, heart rate, and central venous pressure. Transfusion requirements were guided by hematocrit determined by regular blood gas analysis and changes in coagulation parameters (platelets, international normalized ratio (INR), partial thromboplastin time (PTT), and fibrinogen) assessed by routine laboratory analysis. According to the local standards, hematocrit target was $\geq 28 \%$, and platelets and INR were maintained at levels $\geq 80,000 / \mu$ l and $\leq 2$, respectively. Fibrinogen was normalized to values $>1.5 \mathrm{~g} / \mathrm{l}$. With these laboratory targets and the clinical picture including actual blood loss, the amount and speed of transfusion as well as the relation between $\mathrm{RBCs}$ and fresh frozen plasmas (FFPs) were at the discretion of the individual anesthesiologist.

Body core temperature measured by an esophageal temperature probe was maintained between $34^{\circ} \mathrm{C}$ and $36^{\circ} \mathrm{C}$. Hypothermia was only corrected at body core temperature $<34^{\circ} \mathrm{C}$ and signs of coagulopathy. Elevated ICP was treated by increasing depth of sedation including administration of thiopental, adding muscle relaxation, adjusting $\mathrm{paCO}_{2}$, and by infusing mannitol, whenever appropriate. In case of therapy refractory increases in ICP, a further CT was performed, and surgical interventions were evaluated (e.g., craniectomy).

Following the ER/OR phase, all patients were transferred to the trauma surgical ICU where patients were treated according to a standardized ICP/cerebral perfusion pressure (CPP)-guided protocol aided by extended neuromonitoring using BIS EEG and $\mathrm{SjvO}_{2}$ as previously described [25, 38].

\section{Variables}

Clinical data consisted of age, gender, injury severity (injury severity score (ISS) and abbreviated injury scale (AIS) head), number of injured organs, rate of pulmonary complications consisting of functional pulmonary deterioration determined by $\mathrm{paO}_{2} / \mathrm{FiO}_{2}$ ratio and development of structural alterations (pneumonia, acute lung injury (ALI), and ARDS), length of hospitalization on the ICU, and in- hospital mortality. Neuropsychological recovery was assessed by a standardized questionnaire, the eGOS, which was mailed to the patients 6 months following trauma. In case patients or their relatives did not return the questionnaire, an interview via telephone was performed.

During the ER/OR phase, changes in hematocrit, lactate, base excess, $\mathrm{paO}_{2}, \mathrm{paCO}_{2}$, blood glucose, oxygenation ratio $\left(\mathrm{paO}_{2} / \mathrm{FiO}_{2}\right)$, mean arterial pressure, ICP, and CPP were determined by assessing first, last, minimal, and maximal values, respectively.

Blood loss as well as transfusion (RBC, FFP, platelets, and coagulation factors), volume (cristalloids (Ringer Lactate Baxter ${ }^{\circledR}$ ) and colloids (Voluven $6 \%{ }^{\circledR}$; hydroxyethyl starch 130/0.4)), and norepinephrine requirement were investigated.

Changes in platelets, PTT, INR, leukocytes, and Creactive protein were assessed by evaluating the initial values during the ER phase and upon arrival on the ICU.

\section{Database}

As previously described [25], the database was constructed by entering data in predefined columns within a Microsoft Excel $^{\circledR}$ sheet for each individual patient. Then, all individual sheets were transferred to one Microsoft Excel ${ }^{\circledR}$ sheet containing data of all patients. This Microsoft Excel ${ }^{\circledR}$ sheet was then imported into a Microsoft Access ${ }^{\circledR}$ database. Data was entered by CF, SL, JS, and controlled for plausibility and correctness by JFS and SL: following an automated search for incorrect outliers within each column, these values were then corrected by referring to the original patient records.

Relative frequency was determined by first assessing the absolute number of values found within predefined clusters followed by expressing the number of values or incidences per predefined cluster in percent to the absolute number of all values of a certain parameter.

\section{Statistical analysis}

Graphical and statistical analysis was performed using SigmaPlot $^{\circledR}$ and SigmaStat ${ }^{\circledR}$, respectively. Changes between groups (hematocrit clusters) and within predefined hematocrit cluster groups (survivors/non-survivors) were evaluated for statistically significant differences using analysis of variance on ranks with post hoc Dunn's test (multiple comparison) and the Mann-Whitney rank sum test, respectively. Survival probability was determined by log rank analysis (KaplanMeier survival analysis with surviving patients being censored). Multiple logistic regression analysis was performed to identify factors which independently predict outcome by setting outcome as the dependent variable and the different factors (worst values during ER/OR phase, transfusion and 
volume management during the ER/OR phase, and complications and transfusions during the ICU phase) as independent variables. Differences were rated significant at a $p<0.05$.

\section{Results}

Demographic data

Investigated patients were of similar age, predominantly male $(78 \%)$, with the majority of patients presenting with additional injuries (overall average: $67 \%$ multiply injured patients). All patients had similar initial GCS scores (overall average 6) and presented with similar injury scores (ISS and AIS head; Tables 1 and 2). ISS was significantly increased in patients requiring $\mathrm{RBC}$ transfusions (overall median $35 \mathrm{vs.}$ $25 ; p<0.05)$ without a difference between surviving and deceased patients. Deceased patients required craniectomy, placement of pleural drainage, and laparotomy significantly more often than surviving patients, regardless of transfusion requirement and independent of hematocrit reached by the end of the OR phase (craniectomy, 29\% vs. $15 \%$; pleural drainage, $38 \%$ vs. $16 \%$, laparotomy, $9 \%$ vs. $2 \% ; p<0.05$ ).

Changes in hematocrit

By the end of the initial OR phase, hematocrit was significantly decreased in all patients compared to the starting hematocrit, except in those transfused patients who reached hematocrit $>28 \%$ (Fig. 1). Within the predefined hematocrit cluster $>28 \%$, non-transfused patients showed significantly higher hematocrit levels compared to transfused patients (Fig. 1). In patients in whom hematocrit remained $<28 \%$ by the end of the initial OR phase, there was no difference between transfused and non-transfused patients. Overall, by the end of the initial OR phase, there was no difference in hematocrit values between surviving and deceased patients (data not shown).

\section{Blood loss and transfusion requirements}

Blood loss was highest in deceased patients in whom hematocrit remained $<28 \%$ despite transfusions. The hematocrit target set at $>28 \%$ was successfully reached in $45 \%$ of the patients requiring RBC transfusions. Overall, $43 \%$ of the investigated patients received RBCs during the initial OR phase. Depending on their blood loss, patients required more transfusions (Table 1). Large blood losses resulted in low hematocrit levels reached by the end of the OR phase and lead to higher frequency of transfusions; low blood losses were associated with higher hematocrit levels and lower frequency of transfusions (Fig. 2).

Laboratory signs of coagulopathy were observed significantly more often in patients who required RBC transfusions. Hypofibrinogenemia $(<1.7 \mathrm{~g} / \mathrm{l})$ was the
Table 1 Characteristics in deceased and surviving traumatic brain injury patients within different hematocrit clusters reached by the end of the emergency room (ER)/initial operating room (OR) phase. These patients received red blood cell transfusions. Differences are significant between deceased and surviving patients within the hematocrit clusters

\begin{tabular}{|c|c|c|c|c|}
\hline \multirow[t]{2}{*}{ Final hematocrit ${ }_{\mathrm{ER}}$ end } & \multicolumn{2}{|l|}{$<28 \%$} & \multicolumn{2}{|l|}{$\geq 28 \%$} \\
\hline & $\begin{array}{l}\text { Deceased }(N=16) \\
N=31\end{array}$ & Survivors $(N=15)$ & $\begin{array}{l}\text { Deceased }(N=11) \\
N=32\end{array}$ & Survivors $(N=21)$ \\
\hline Final hematocrit ${ }_{E R}$ end $(\%)$ & 24,23 to 27 & 26,22 to 27 & 30,28 to 39 & 31,28 to 34 \\
\hline Percent & $48 \%$ & $52 \%$ & $34 \%$ & $66 \% *$ \\
\hline ISS & 30,16 to 66 & 37,20 to 57 & 34,25 to 50 & 38,16 to 70 \\
\hline ICU length (days; median, range) & $2.5,2$ to 12 & 17,3 to 40 & 3,2 to 23 & 16,3 to 51 \\
\hline Blood loss (1) & $3,0.5$ to $7^{*}$ & $1.5,0.5$ to 15 & $0.4,0.1$ to 6 & $1.5,0.1$ to 5 \\
\hline Colloids (1) & $1.5,0.5$ to 3 & $1.5,0.5$ to 3 & $1.6,0.5$ to 6 & $1.5,0.5$ to 4.3 \\
\hline Cristalloids (1) & $3.4,1.3$ to 7.5 & $2.4,1.5$ to 8.5 & $4,0.9$ to 18 & $3.2,0.8$ to 5 \\
\hline Balance (1) & $3.9,-0.6$ to 7.95 & $2.9,-5$ to 7.6 & $2.5,0$ to 11 & $2.6,-2$ to 11 \\
\hline Norepinephrine $(\mu \mathrm{g} / \mathrm{kg} / \mathrm{min})$ & $0.36,0.07$ to $1.9 *$ & $0.2,0.03$ to 1.6 & $0.2,0.03$ to $1.3^{*}$ & $0.12,0.03$ to 1.1 \\
\hline MAP min (mmHg) & 70,45 to 135 & 70,35 to 90 & 65,40 to 85 & 65,25 to 95 \\
\hline ICP $\max (\mathrm{mmHg})$ & 51,28 to $104^{*}$ & 17,2 to 105 & 48,20 to $54^{*}$ & 16,5 to 50 \\
\hline $\mathrm{CPP} \min (\mathrm{mmHg})$ & 59,22 to 89 & 58,35 to 74 & 60,35 to 73 & 54,30 to 80 \\
\hline
\end{tabular}

ISS injury severity score, $M A P$ mean arterial pressure, $I C P$ intracranial pressure, $C P P$ cerebral perfusion pressure, min minimum, max maximum ${ }^{*} p<0.05$ (Mann-Whitney test) 
Table 2 Details in deceased and surviving traumatic brain injury patients within different hematocrit clusters reached by the end of the emergency room (ER)/initial operating room (OR) phase. These patients did not receive any red blood cell transfusions. Differences are significant between deceased and surviving patients within the different hematocrit clusters

\begin{tabular}{|c|c|c|c|c|}
\hline \multirow[t]{3}{*}{ Final hematocrit ${ }_{\mathrm{ER}}$ end } & \multicolumn{2}{|l|}{$<28 \%$} & \multicolumn{2}{|l|}{$\geq 28 \%$} \\
\hline & Deceased $(N=1)$ & Survivors $(N=5)$ & Deceased $(N=23)$ & Survivors $(N=47)$ \\
\hline & $N=6$ & & $N=70$ & \\
\hline Final hematocrit $\mathrm{ER}_{\mathrm{ER}}(\%)$ & 23 & 26,25 to 27 & 36,29 to 47 & 34,28 to 47 \\
\hline Percent & $17 \%$ & $83 \%$ & $33 \%$ & $67 \% *$ \\
\hline ISS & 50 & 25,14 to 34 & 25,19 to 50 & 25,9 to 57 \\
\hline Blood loss (1) & 1.5 & $0.4,0.4$ to 1 & $0.2,0$ to 0.6 & $0.2,0$ to 1 \\
\hline Colloids (1) & 0.9 & 1,1 to 1.5 & $0.5,0$ to 2.5 & $0.6,0.25$ to 3 \\
\hline Crystalloids (1) & 2 & $1.8,1.5$ to 2.2 & $1.6,0.4$ to 5 & $2,0.2$ to 4 \\
\hline Balance (1) & 0.9 & $0.6,-2.7$ to 1.8 & $0.6,-2.3$ to 4.5 & $1,-1.8$ to 3 \\
\hline Norepinephrine $(\mu \mathrm{g} / \mathrm{kg} / \mathrm{min})$ & 0.036 & $0.11,0.02$ to 0.2 & $0.06,0$ to 0.32 & $0.1,0.02$ to 0.72 \\
\hline MAP min (mmHg) & 55 & 70,65 to 80 & 80,60 to 105 & 70,45 to 100 \\
\hline ICP $\max (\mathrm{mmHg})$ & 42 & 13,6 to 28 & 22,4 to 40 & 12,2 to 50 \\
\hline CPP $\min (\mathrm{mmHg})$ & 13 & 62,54 to 70 & 69,42 to 88 & 66,32 to 90 \\
\hline
\end{tabular}

ISS injury severity score, $M A P$ mean arterial pressure, $I C P$ intracranial pressure, $C P P$ cerebral perfusion pressure, $\min$ minimum, $\max$ maximum ${ }^{*} p<0.05$ (Mann-Whitney test)

leading pathologic finding in $41 \%$ of transfused patients vs. $7.9 \%$ in non-transfused patients, followed by thrombocytopenia $(<80,000 / \mu \mathrm{l})$ in $11 \%$ vs. $0 \%$, PTT $>40 \mathrm{~s}$ in $9.5 \%$ vs. $2.6 \%$, and INR $>2$ in $2.6 \%$ vs. $1.6 \%$.

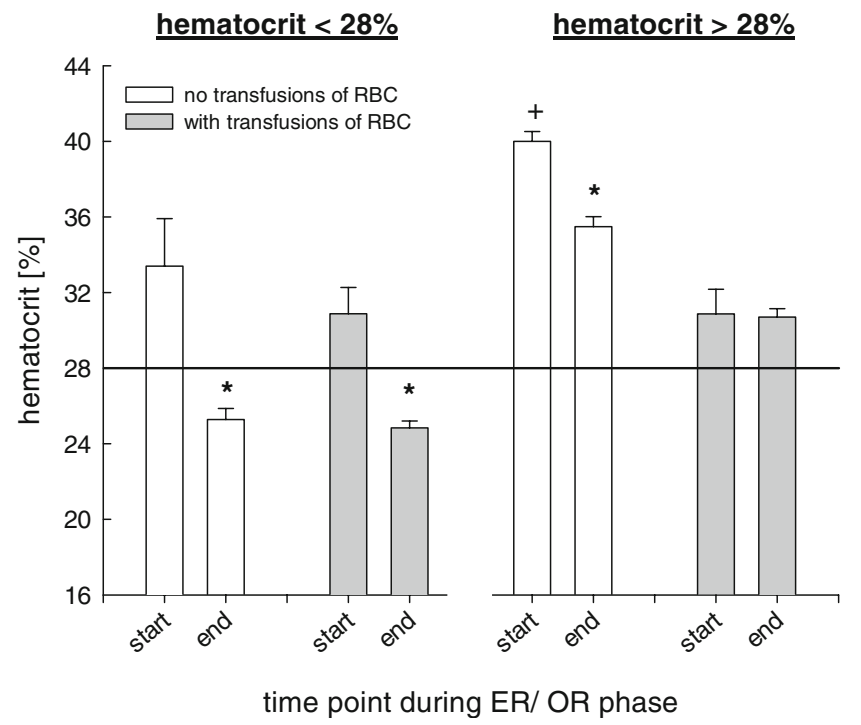

Fig. 1 Changes in hematocrit values at specific time points (beginning and end of the initial operating room (OR) phase) in transfused (gray bars) and non-transfused patients (white bars). Changes in hematocrit were evaluated in predefined hematocrit clusters determined by the end of the OR phase comparing $<28 \%$ and $\geq 28 \%$. By the end of the OR phase, hematocrit was significantly decreased $(* p, 0.05$, Mann-Whitney test)

\section{Lab values and temperature}

Overall, there were no significant differences between lowest $\mathrm{pH}$, highest lactate, lowest base excess, lowest $\mathrm{paO}_{2}$, lowest $\mathrm{paCO}_{2}$, lowest and highest glucose, and lowest $\mathrm{paO}_{2} / \mathrm{FiO}_{2}$ ratio across the investigated subgroups (data not shown).

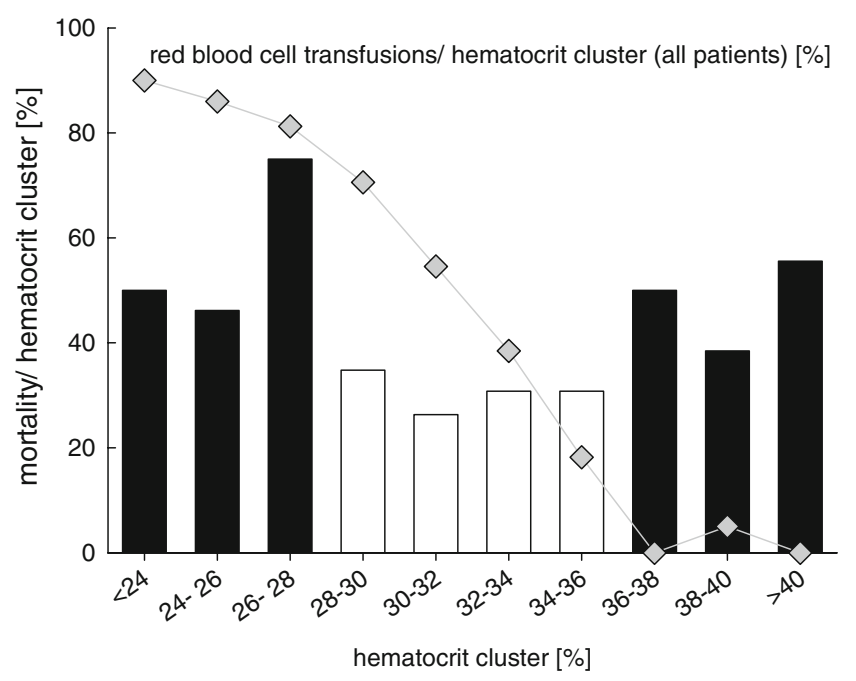

Fig. 2 Relative frequency of red blood cell transfusions (gray symbols) decreased with increasing hematocrit levels reached by the end of the emergency room phase. Mortality calculated for predefined hematocrit clusters was lowest within hematocrit levels ranging from $28 \%$ to $36 \%$ (white bars) 


\section{Mortality}

Overall survival rate was $60 \%$ (83 survivors, 56 deceased; total 139 patients; Tables 1 and 2). As suggested by Fig. 2, mortality was lowest in patients reaching hematocrit values between $28 \%$ and $30 \%$ compared to lower and higher hematocrit levels (Fig. 2). However, calculated survival probability (Kaplan-Meier analysis) excluded a significant impact of transfusions and also excluded a significant impact of different hematocrit levels reached by the end of the ER phase with and without concomitant transfusions in the different hematocrit clusters (Fig. 3). There was a trend to lowest survival probability in transfused patients in whom hematocrit remained $<28 \%$ at the end of the OR phase. A trend towards highest survival probability was seen in patients in whom hematocrit exceeded $28 \%$ without having been transfused. This effect, however, was lost after 4 weeks.

Morbidity determined by eGOS 6 months after severe TBI

Surviving patients showed a good recovery with a median eGOS of 6.5 (all groups) determined 6 months after injury, irrespective of transfusion requirements (data not shown). Based on multiple logistic regression analysis, eGOS was not influenced by the hematocrit reached by the end of the initial OR phase or the lowest hematocrit level and was neither influenced by the transfusion practice nor the

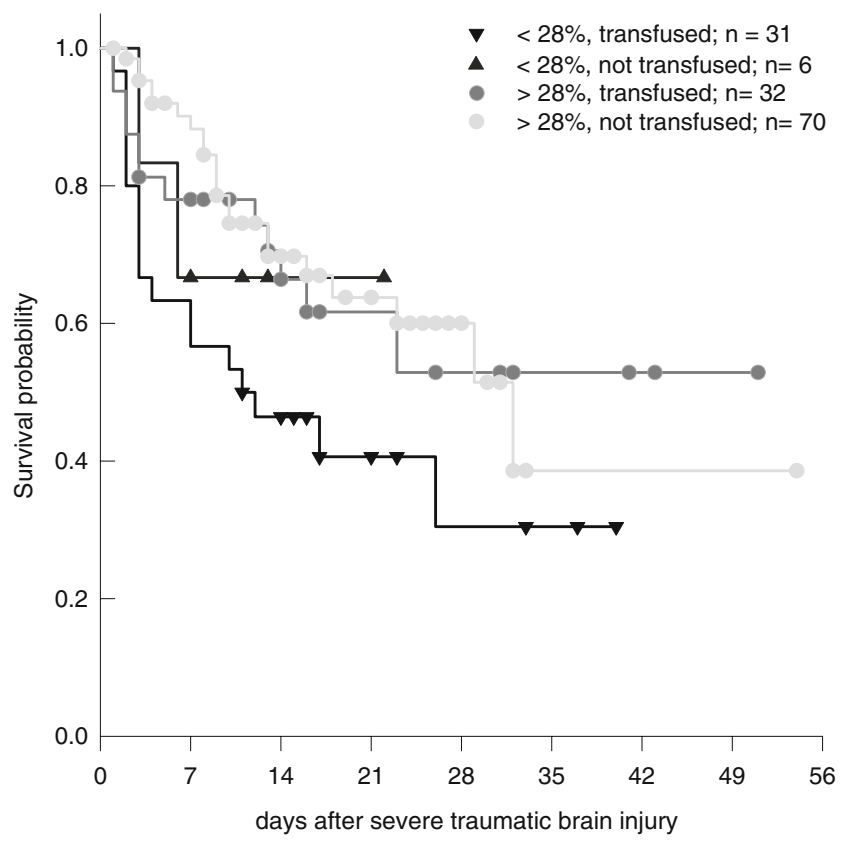

Fig. 3 Log rank analysis of calculated survival probability (KaplanMeier) excluded a significant influence of different hematocrit levels above $28 \%$ and below $28 \%$ reached by the end of the initial operating room phase on mortality following severe traumatic brain injury volume management. However, eGOS was dependent on highest ICP and lowest CPP measured during the initial OR phase as determined by multiple logistic regression analysis (ICP $\max , p=0.007$; CPP $\min ; p=0.017$ ).

ICP and CPP during the initial OR phase

Highest ICP values were measured in patients who died later on compared to surviving patients (Tables 1 and 2). CPP was lowest in deceased patients in whom hematocrit remained $<28 \%$ at the end of the initial OR phase (Tables 1 and 2).

Complications and duration of hospitalization

Overall, there was no significant difference in rate of pulmonary complications assessed by pathologic $\mathrm{paO}_{2} /$ $\mathrm{FiO}_{2}$ values, irrespective of transfusion requirements and reached hematocrit (data not shown).

Length of stay on the ICU in surviving patients was similar in all patients, irrespective of transfusion requirements (Tables 1 and 2).

Deceased patients presented with a significantly shorter length of hospitalization in the ICU compared to surviving patients (Tables 1 and 2).

Fluid management, calculated fluid balance, and norepinephrine administration

Highest amounts of fluids, calculated balance, and required norepinephrine were found in deceased patients, mainly within the hematocrit cluster $<28 \%$ (Tables 1 and 2). Patients not requiring transfusions also needed significantly less volume administration and reached a significantly less positive fluid balance by the end of the OR phase (Tables 1 and $2 ; p<0.05)$.

\section{Discussion}

Following severe TBI, contemporary transfusion practice aimed at maintaining hematocrit $\geq 28 \%$ was not associated with an increase in mortality as determined by the KaplanMeier survival probability and was not associated with an increased rate of pulmonary complications.

According to the present retrospective analysis, mortality was strongly influenced by significantly increased ICP and decreased CPP during the initial OR phase. Death in these patients was always due to intractable ICP with signs of severe brain stem damage due to supra- and infratentorial herniation.

It is possible that a low hematocrit $<28 \%$ could have contributed to an increased ICP due to sustained cerebral 
vasodilation as observed under experimental $[6,12]$ and clinical conditions [5] or decreased oxygenation [11]. These effects occur concentration-dependently [11] and aggravate underlying brain damage $[7,12]$. As shown by van Beek et al., decreased hemoglobin $(<8 \mathrm{~g} / \mathrm{dl})$ was associated with poorer outcome following severe TBI [39]. Anemia was also a function of severe arterial hypotension; and on average, however, hemoglobin was similar in all patients, regardless of outcome. Potentially aggravating effects, however, cannot be differentiated by the present study since (1) the patients within the low hematocrit group already presented with a significantly decreased hematocrit at the beginning of the OR phase due to ongoing hemorrhage, and (2) ICP was not measured until after specific treatment modalities had been started. Thus, we cannot determine if the ICP had already been pathologically elevated before or at the beginning of ongoing hemorrhage and if ICP had been lower had the hematocrit been increased more aggressively before inserting an ICP probe. The facts that estimated ISS, blood loss, and transfusion requirements were comparable in deceased and surviving patients within the predefined hematocrit clusters reached by the end of the OR phase strongly suggest that the pathologically elevated ICP was a stronger determinant of mortality than the transfusion practice or reached hematocrit. This is in line with results reviewed by Treggiari et al. showing that persistently elevated ICP exceeding $20 \mathrm{mmHg}$ is associated with increased mortality and morbidity [36]. In addition to the significantly increased ICP, CPP had also been significantly decreased in those patients who died later on. Hypotension-induced insufficient cerebral perfusion and oxygenation strongly increases mortality and morbidity aggravated by additional insults as, e.g., hypoxia [21].

Anemia and secondary brain damage

Under physiologic conditions, cerebral oxygen supply can be maintained in situations of decreased hematocrit to prevent cerebral hypoxia [46] by increased cardiac output and elevated cerebral oxygen extraction [17]. In addition to systemic compensatory processes, local adaptive alterations have been described. In this context, cerebral blood flow is increased due to cerebral anemia-induced vasodilation [40]. Concomitantly, however, oxygen extraction is significantly increased, and tissue oxygen is reduced [40], thereby reflecting insufficient compensation with a sustained risk for additional brain damage. Cerebral blood flow is inversely proportional to blood oxygen content [34] and viscosity [35] which are reduced by anemia. In healthy volunteers [43, 44], induced hemodilution decreasing hemoglobin to $7 \mathrm{~g} / \mathrm{dl}$ (hematocrit $21 \%$ ) can be compensated. Further decrease to $5 \mathrm{~g} / \mathrm{dl}(15 \%)$, however, resulted in neuropsychological impairment, which was reversed by transfusing RBCs [43, 45]. In orthopedic patients, a decrease in hematocrit to $24 \%$ (hemoglobin $8 \mathrm{~g} / \mathrm{dl}$ ) was associated with signs of impaired cerebral oxygenation [11]. Based on these findings, the lower acceptable hematocrit should remain above $24 \%$ to avoid impairing cerebral oxygenation and prevent induction of additional brain damage as shown under experimental conditions [12]. Hare et al. could also demonstrate that underlying brain damage increased hypoxemia-induced injury [12].

As suggested by several authors $[1,8,24]$, reduction of the transfusion threshold to a hematocrit level of $21-27 \%$ (hemoglobin 7-9 g/dl) appears not to endanger TBI patients. However, we must keep in mind that these recommended values stem from stable and well-controlled ICU conditions $[1,8,18,24,30]$. To date, we are still lacking information regarding the initial unstable OR phase. Thus, a general recommendation cannot be given at this time point. Since the hematocrit target used at our hospital was $28 \%$, we cannot exclude that the lower level of optimal hematocrit could even be lower. A prospective randomized trial including refined neuropsychological testing is required to address this issue.

Under conditions of compromised microcirculation which predominates the early phase following TBI as shown experimentally $[15,32]$, an additional pathologic influence mediated by transfused RBCs could aggravate underlying injury. In this context, transfusion of RBCs (28 days old) significantly impaired microcirculatory perfusion and oxygenation and increased local inflammatory response under experimental conditions [9, 37]. Whether these findings will also contribute to the activated local thrombotic and inflammatory processes within the injured brain [31, 32], thereby aggravating underlying damage, remains to be determined under clinical conditions. Although not significant, transfusions were associated with a trend to decreased survival during the first 4 weeks following severe TBI. This was mainly observed in patients in whom hematocrit remained below $28 \%$ despite transfusions (Fig. 3). It remains unclear if transfusions per se or insufficient correction of hematocrit contributed to this observed trend.

\section{Limitations of the present study}

The present retrospective study is purely observational and is limited by its lack in controlled measures as the transfusion trigger, time of delay, speed of RBC transfusion as well as administration of FFPs, platelets, and coagulation factors were at the discretion of the treating anesthesiologists, trauma surgeons, and neurosurgeons. Thus, the present study does not allow to determine the additional influence of administration of FFPs, platelets, and coagulation factors or the impact of different $\mathrm{RBC}$ to FFP ratios 
which have been shown to significantly influence mortality [4]. Furthermore, age of transfused RBCs, which have also been shown to increase mortality in patients receiving larger amounts of $\mathrm{RBCs}$ [42] and impair increase in cerebral oxygen [16], was not specifically addressed in the present study. Under emergency conditions in case of ongoing hemorrhage, however, time delay due to selecting only young RBCs (storage duration $<2$ weeks) is impossible. Due to individual and priority-dependent situations, more specific monitoring of cellular deterioration with the aim of defining an individual transfusion threshold by using, e.g., ptiO $\mathrm{p}_{2}$ and microdialysis during the OR phase is merely impossible. This is due to time restraints, which are immanent to the diagnostic and surgical procedures, and the technical issues in terms of prolonged equilibration time, which do not allow for physicians to wait for valid values obtained by these techniques. During stable ICU conditions, transfusion requirement can be guided by measuring brain tissue oxygenation [18, 30]. Application of nearinfrared spectroscopy (NIRS) sensors and insertion of a jugular bulb catheter, however, could prove helpful in guiding and fine-tuning transfusion practice also under extreme OR conditions.

\section{Conclusions}

As suggested by the present retrospective analysis, correction of hematocrit values above $28 \%$ during the initial OR phase following severe TBI does not appear mandatory. The lowest possible hematocrit level, however, must still be determined. For this, more detailed monitoring of cerebral metabolism and oxygenation during the initial OR phase by using, e.g., jugular venous blood gas sampling or NIRS technology are required to determine safe hematocrit levels, identify detrimental hematocrit levels, and thus define optimal and individual transfusion triggers.

Acknowledgements The help of the ER and ICU nursing staff in collecting clinical data is gratefully acknowledged.

Conflict of interest None.

Funding This study was supported in part by grants from the SUVA funds to JFS and RS.

\section{References}

1. Carlson AP, Schermer CR, Lu SW (2006) Retrospective evaluation of anemia and transfusion in traumatic brain injury. J Trauma 61:567-571

2. Cherry T, Steciuk M, Reddy VV, Marques MB (2008) Transfusion-related acute lung injury: past, present, and future. Am J Clin Pathol 129:287-297
3. Corwin HL, Gettinger A, Pearl RG, Fink MP, Levy MM, Abraham E, MacIntyre NR, Shabot MM, Duh MS, Shapiro MJ (2004) The CRIT Study: anemia and blood transfusion in the critically ill-current clinical practice in the United States. Crit Care Med 32:39-52

4. Duchesne JC, Hunt JP, Wahl G, Marr AB, Wang YZ, Weintraub SE, Wright MJ, McSwain NE Jr (2008) Review of current blood transfusions strategies in a mature level I trauma center: were we wrong for the last 60 years? J Trauma 65:272-276

5. Ekelund A, Reinstrup P, Ryding E, Andersson AM, Molund T, Kristiansson KA, Romner B, Brandt L, Säveland H (2002) Effects of iso- and hypervolemic hemodilution on regional cerebral blood flow and oxygen delivery for patients with vasospasm after aneurysmal subarachnoid hemorrhage. Acta Neurochir (Wien) 144:703-712

6. Frietsch T, Lenz C, Kuschinsky W, Waschke KE (2004) Effects of chronic isovolaemic haemodilution on regional cerebral blood flow in conscious rats. Eur J Anaesthesiol 21:53-59

7. Ge YL, Lv R, Zhou W, Ma XX, Zhong TD, Duan ML (2007) Brain damage following severe acute normovolemic hemodilution in combination with controlled hypotension in rats. Acta Anaesthesiol Scand 51:1331-1337

8. George ME, Skarda DE, Watts CR, Pham HD, Beilman GJ (2008) Aggressive red blood cell transfusion: no association with improved outcomes for victims of isolated traumatic brain injury. Neurocrit Care 8:337-343

9. Gonzalez AM, Yazici I, Kusza K, Siemionow M (2007) Effects of fresh versus banked blood transfusions on microcirculatory hemodynamics and tissue oxygenation in the rat cremaster model. Surgery 141:630-639

10. Habib RH, Zacharias A, Schwann TA, Riordan CJ, Durham SJ, Shah A (2003) Adverse effects of low hematocrit during cardiopulmonary bypass in the adult: should current practice be changed? J Thorac Cardiovasc Surg 125:1438-1450

11. Han SH, Ham BM, Oh YS, Bahk JH, Ro YJ, Do SH, Park YS (2004) The effect of acute normovolemic haemodilution on cerebral oxygenation. Int J Clin Pract 58:903-906

12. Hare GM, Mazer CD, Hutchison JS, McLaren AT, Liu E, Rassouli A, Ai J, Shaye RE, Lockwood JA, Hawkins CE, Sikich N, To K, Baker AJ (2007) Severe hemodilutional anemia increases cerebral tissue injury following acute neurotrauma. J Appl Physiol 103:1021-1029

13. Hébert PC, Wells G, Blajchman MA, Marshall J, Martin C, Pagliarello G, Tweeddale M, Schweitzer I, Yetisir E (1999) A multicenter, randomized, controlled clinical trial of transfusion requirements in critical care. Transfusion Requirements in Critical Care Investigators, Canadian Critical Care Trials Group. N Engl J Med 340:409-417

14. Klein HG, Spahn DR, Carson JL (2007) Red blood cell transfusion in clinical practice. Lancet 370:415-426

15. Kroppenstedt SN, Thomale UW, Griebenow M, Sakowitz OW, Schaser KD, Mayr PS, Unterberg AW, Stover JF (2003) Effects of early and late intravenous norepinephrine infusion on cerebral perfusion, microcirculation, brain-tissue oxygenation, and edema formation in brain-injured rats. Crit Care Med 31:2211-2221

16. Leal-Noval SR, Muñoz-Gómez M, Arellano-Orden V, MarínCaballos A, Amaya-Villar R, Marín A, Puppo-Moreno A, Ferrándiz-Millón C, Flores-Cordero JM, Murillo-Cabezas F (2008) Impact of age of transfused blood on cerebral oxygenation in male patients with severe traumatic brain injury. Crit Care Med 36:1290-1296

17. Leal-Noval SR, Múñoz-Gómez M, Murillo-Cabezas F (2008) Optimal hemoglobin concentration in patients with subarachnoid hemorrhage, acute ischemic stroke and traumatic brain injury. Curr Opin Crit Care 14:156-162

18. Leal-Noval SR, Rincón-Ferrari MD, Marin-Niebla A, Cayuela A, Arellano-Orden V, Marín-Caballos A, Amaya-Villar R, Ferrándiz- 
Millón C, Murillo-Cabeza F (2006) Transfusion of erythrocyte concentrates produces a variable increment on cerebral oxygenation in patients with severe traumatic brain injury: a preliminary study. Intensive Care Med 32:1733-1740

19. Madjdpour C, Spahn DR, Weiskopf RB (2006) Anemia and perioperative red blood cell transfusion: a matter of tolerance. Crit Care Med 34(5 Suppl):S102-S108

20. Marik PE, Corwin HL (2008) Efficacy of red blood cell transfusion in the critically ill: a systematic review of the literature. Crit Care Med 36:2667-2674

21. McHugh GS, Engel DC, Butcher I, Steyerberg EW, Lu J, Mushkudiani N, Hernández AV, Marmarou A, Maas AI, Murray GD (2007) Prognostic value of secondary insults in traumatic brain injury: results from the IMPACT study. J Neurotrauma $24: 287-293$

22. McIntyre LA, Fergusson DA, Hutchison JS, Pagliarello G, Marshall JC, Yetisir E, Hare GM, Hébert PC (2006) Effect of a liberal versus restrictive transfusion strategy on mortality in patients with moderate to severe head injury. Neurocrit Care $5: 4-9$

23. McIntyre LA, Hebert PC (2006) Can we safely restrict transfusion in trauma patients? Curr Opin Crit Care 12:575-583

24. McIntyre L, Hebert PC, Wells G, Fergusson D, Marshall J, Yetisir E, Blajchman MJ, Canadian Critical Care Trials Group (2004) Is a restrictive transfusion strategy safe for resuscitated and critically ill trauma patients? J Trauma 57:563-568

25. Meier R, Béchir M, Ludwig S, Sommerfeld J, Keel M, Steiger P, Stocker R, Stover JF (2008) Differential temporal profile of lowered blood glucose levels (3.5 to $6.5 \mathrm{mmol} / \mathrm{l}$ versus 5 to $8 \mathrm{mmol} / \mathrm{l})$ in patients with severe traumatic brain injury. Crit Care 12:R98

26. Meixensberger J, Kunze E, Barcsay E, Vaeth A, Roosen K (2001) Clinical cerebral microdialysis: brain metabolism and brain tissue oxygenation after acute brain injury. Neurol Res 23:801-806

27. Meixensberger J, Renner C, Simanowski R, Schmidtke A, Dings J, Roosen K (2004) Influence of cerebral oxygenation following severe head injury on neuropsychological testing. Neurol Res $26: 414-417$

28. Rosenthal G, Hemphill JC, Sorani M, Martin C, Morabito D, Meeker M, Wang V, Manley GT (2008) The role of lung function in brain tissue oxygenation following traumatic brain injury. $\mathrm{J}$ Neurosurg 108:59-65

29. Sarrafzadeh AS, Kiening KL, Callsen TA, Unterberg AW (2003) Metabolic changes during impending and manifest cerebral hypoxia in traumatic brain injury. Br J Neurosurg 17:340-346

30. Smith MJ, Stiefel MF, Magge S, Frangos S, Bloom S, Gracias V, Le Roux PD (2005) Packed red blood cell transfusion increases local cerebral oxygenation. Crit Care Med 33:1104-1108

31. Thomale UW, Bender M, Casalis P, Rupprecht S, Griebenow M, Neumann K, Woiciechowsky C, Unterberg AW, Stover JF (2007) Tacrolimus depresses local immune cell infiltration but fails to reduce cortical contusion volume in brain-injured rats. Immunobiology 212:567-576

32. Thomale UW, Kroppenstedt SN, Beyer TF, Schaser KD, Unterberg AW, Stover JF (2002) Temporal profile of cortical perfusion and microcirculation after controlled cortical impact injury in rats. J Neurotrauma 19:403-413

33. Tinmouth A, Fergusson D, Yee IC, Hébert PC, ABLE Investigators; Canadian Critical Care Trials Group (2006) Clinical consequences of red cell storage in the critically ill. Transfusion 46:2014-2027

34. Tomiyama Y, Brian JE Jr, Todd MM (2000) Plasma viscosity and cerebral blood flow. Am J Physiol Heart Circ Physiol 279:H1949 H1954

35. Tomiyama Y, Jansen K, Brian JE Jr, Todd MM (1999) Hemodilution, cerebral O2 delivery, and cerebral blood flow: a study using hyperbaric oxygenation. Am J Physiol 276:H1190H1196

36. Treggiari MM, Schutz N, Yanez ND, Romand JA (2007) Role of intracranial pressure values and patterns in predicting outcome in traumatic brain injury: a systematic review. Neurocrit Care 6:104-112

37. Tsai AG, Cabrales P, Intaglietta M (2004) Microvascular perfusion upon exchange transfusion with stored red blood cells in normovolemic anemic conditions. Transfusion 44:1626-1634

38. Tschuor C, Asmis LM, Lenzlinger PM, Tanner M, Härter L, Keel M, Stocker R, Stover JF (2008) In vitro norepinephrine significantly activates isolated platelets from healthy volunteers and critically ill patients following severe traumatic brain injury. Crit Care 12:R80

39. Van Beek JG, Mushkudiani NA, Steyerberg EW, Butcher I, McHugh GS, Lu J, Marmarou A, Murray GD, Maas AI (2007) Prognostic value of admission laboratory parameters in traumatic brain injury: results from the IMPACT study. J Neurotrauma 24:315-328

40. van Bommel J, Trouwborst A, Schwarte L, Siegemund M, Ince C, Henny ChP (2002) Intestinal and cerebral oxygenation during severe isovolemic hemodilution and subsequent hyperoxic ventilation in a pig model. Anesthesiology 97:660-670

41. Vincent JL, Baron JF, Reinhart K, Gattinoni L, Thijs L, Webb A, Meier-Hellmann A, Nollet G, Peres-Bota D, ABC (Anemia and Blood Transfusion in Critical Care) Investigators (2002) Anemia and blood transfusion in critically ill patients. JAMA 288:14991507

42. Weinberg JA, McGwin G Jr, Griffin RL, Huynh VQ, Cherry SA 3rd, Marques MB, Reiff DA, Kerby JD, Rue LW 3rd (2008) Age of transfused blood: an independent predictor of mortality despite universal leukoreduction. J Trauma 65:279-282

43. Weiskopf RB, Feiner J, Hopf H, Lieberman J, Finlay HE, Quah C, Kramer JH, Bostrom A, Toy P (2006) Fresh blood and aged stored blood are equally efficacious in immediately reversing anemiainduced brain oxygenation deficits in humans. Anesthesiology 104:911-920

44. Weiskopf RB, Kramer JH, Viele M, Neumann M, Feiner JR, Watson JJ, Hopf HW, Toy P (2000) Acute severe isovolemic anemia impairs cognitive function and memory in humans. Anesthesiology 92:1646-1652

45. Weiskopf RB, Toy P, Hopf HW, Feiner J, Finlay HE, Takahashi M, Bostrom A, Songster C, Aminoff MJ (2005) Acute isovolemic anemia impairs central processing as determined by P300 latency. Clin Neurophysiol 116:1028-1032

46. Zauner A, Daugherty WP, Bullock MR, Warner DS (2002) Brain oxygenation and energy metabolism: part I-biological function and pathophysiology. Neurosurgery 51:289-301

This paper addresses pertinent questions related with the acute, presumably cranial and extracranial, surgical management of traumatic brain injury (TBI) patients. How tolerable is the blood loss, due to traumatic loss or bleeding during surgical procedures, either in terms of blood volume or hemoglobin levels, without jeopardizing brain oxygen supply and, consequently, outcome? In addition, which objectives should be aimed for if the patient should be transfused?

The study design is very similar to the design of Clifton hypothermia trial, as it divides TBI patients in two predefined clusters based on the initial hematocrit level, using a hematocrit $28 \%$ as a cutoff. Further exploring the similitude between these two studies, it also evaluates the impact of blood transfusion or abstention of transfusion, in both cohorts of patients.

This study accrues a significant number of patients, and the statistical analysis is very robust, which altogether confers a considerable power to the conclusions. As shown by previous research, it demonstrates that substrate delivery, including oxygen, may not be the main problem in TBI pathophysiology, reason why 
increasing hematocrit, and thus oxygen-carrying capacity, is not necessarily associated with a decrease in morbidity and mortality.

In normal physiological conditions, the maximal capacity of oxygen transport and unload to the brain is achieved at a hemoglobin level around $10 \mathrm{mg} / \mathrm{dl}$. In head-injured patients, this axiom is probably questionable because the injury itself carries changes in patterns of oxygen delivery and consumption, as well as cerebral microcirculation. Many of these patients are either on increased inspired fraction of oxygen or under the effect of drugs, as mannitol, that have favorable rheological properties, or are sedated to improve the flow/metabolism mismatch. Furthermore, the occurrence of extracranial injuries that often requires surgical repair adds to secondary brain lesions due to a higher incidence of hypoxia and hypotension in these patients.

I suppose that some interesting conclusions can be drawn from this study:

- It is better for head-injured patients if a blood transfusion is not needed.
- Raising the hematocrit is not a technical problem, but it does not translate into an increased outcome, probably because patients that need a transfusion are those with higher incidence of hypoxia and hypotension due to extracranial injuries or higher surgical blood loss. The importance of the severity of primary injuries is expressed in deceased patients with low hematocrit that fail to increase hematocrit with transfusion.

- As shown in the prolific Fig. 3, mortality tends to be higher in patients with low $(28 \%)$ or in patients with higher $(>36 \%)$ initial hematocrit levels, as well as mortality is independent of blood transfusion.

- The survival probability of non-transfused patient with $<28 \%$ hematocrit by the end of the OR phase is similar to those transfused patients with $>28 \%$ hematocrit, thus outshining the effect of transfusion on raising the hematocrit.

Oscar Alves

Porto, Portugal 